\title{
Obligatory Movement Operations for Verbal Roots in Najdi Arabic
}

\author{
Al Qahtani Khulud, Al Zahrani Mohammad*
}

Taif University, Taif, Saudi Arabia, Foreign Languages Department (FLD) Fellow, Advance HEA, UK

Corresponding Author: Al Zahrani Mohammad, E-mail: m.zah@tu.edu.sa/moali66@hotmail.com

\section{ARTICLE INFO}

Article history

Received: October 16, 2019

Accepted: December 27, 2019

Published: February 29, 2020

Volume: 11 Issue: 1

Advance access: February 2020

Conflicts of interest: None

Funding: None

Key words:

Verb Movement,

Word Order,

Najdi Arabic

\begin{abstract}
This paper focuses on the obligatory movement operations that Najdi Arabic (NA) verb forms must undergo to satisfy the morphosyntactic requirements within the minimalist program (MP). Recall that the practice of the MP syntactic theory, including its further advancements, proposed by Chomsky $(1995,2000,2001)$ springs from the fact that the grammar of a language starts basically from the lexicon from which suitable words are selected to form clauses. The selected words undergo some syntactic operations such as Merge, by which larger constituents are formed, and Move, by which the formed constituents move to higher positions in the hierarchy to fulfil some specific syntactic purposes. When the elements have undergone the operations of Merge and Move they are spelled out into phonetic forms (PF) and logical forms (LF). In light of this, we argue that NA verbs start out as roots in the head of VP before merging with the vocalic affixes in the head of Tax-AspP to satisfy the subjectverb agreement requirements and mark the aspect features. Perfective verb forms must then continue to move to T to merge with the past tense abstract features while imperfective forms stay in Tax-AspP. The thematic subject is generated in Spec,VP; it may stay there to derive the VSO order, or move higher to derive the SVO order. The findings show that obligatory movements indicate interactions between the functional categories of TP, Tax-AspP and VP: NA verbal roots obligatorily move to Tax-Asp to derive (im)perfective forms; perfectives obligatorily move to T.
\end{abstract}

\section{INTRODUCTION}

NA clauses show VSO and SVO word orders. The aim of this paper is to explore how these different word orders are formed and what the basic word order is. To achieve this aim, the paper focuses on the obligatory movement of (im) perfective verb forms, and argues that this movement, being obligatory, derives the basic VSO order. Movement operations and the agreement system are two of the great mysteries of natural languages; they occur by distinct operations but they work together to enhance human languages with enormous expressive power (Miyagawa, 2009). They occur in Najdi Arabic (henceforth, NA) to fulfil some linguistic purposes by which verb forms inflect for aspect, representing perfective or imperfective forms, and for full agreement with their subjects, which may also move to positions higher than the verb forms. How and why does the verb movement occur in NA?

The X-bar theory considers the relations between basic elements of a verbal clause: (V)erb, (S)ubject, and (O)bject. The subject $(\mathrm{S})$ is the specifier of the verb $(\mathrm{V})$. The verb $(\mathrm{V})$ is the head $(\mathrm{H})$ and the object $(\mathrm{O})$ is the complement of the head. This relation suggests a SubjectVerb-Object word order (SVO). This is on a par with Kayne's (1994: 47) claim that all languages present "S-H-C order" where S-H-C stand for Specifier, Head and Complement respectively. However, we argue in this paper that the movement of the verbal root from $\mathrm{V}$ to a higher position is obligatory, so that the verb inflects for aspect and shows full subject-verb agreement. The subject movement is optional, so it can stay in situ, in the specifier position of the VP shell. The obligatory movement of the verbal root with the subject in situ derives the basic VSO order in NA. When the subject moves higher than the verb position, the SVO order is achieved. It is important to emphasize that investigating the possible word order structures in NA will take us far afield, so the paper limits its attention to the obligatory movement of the verb forms, which in turn shows the basic word order. Then it shows how an alternative word order may be derived.

The paper is organized as follows. The following section briefly presents an overview of NA and its syntax. Section 3 throws light on some basic assumptions and findings within the Minimalist Program (MP) that help in examining the NA verb movement operation. Section 4 and its three sub-sections explore the NA verb and subject movement operations, and Section 4 concludes the paper.

\section{SYNTAX OF NAJDI ARABIC}

Classical Arabic is a VSO language, but some Arabic dialects are SVO (Hassan, 1987). Sometimes clauses can show the VOS order. Traditionally, Arabic clauses are classified 
according to the first word in the clause (Ryding, 2005). Thus, clauses starting with a noun phrase are nominal clauses, and clauses starting with verbs are verbal clauses. This proposes that NA has two main word-order clause types. The first type is a subject-initial clause (SVO), also known as a nominal clause (dzumla ismiyah). Clauses of this type begin with a noun or a noun phrase known as mubtadaa (Topic), which is followed by a complement, xabar (Comment), as shown in example (1a) below. The second type of clauses is a verb-initial clause (VSO), also known as a verbal clause (dzumla fisliyah). Clauses of this type begin with a verb followed by a noun or a noun phrase, i.e., a subject, as in (1b). There are differences between classical Arab grammarians and many contemporary linguists with respect to the analysis of the nominal and verbal clauses. Classical Arab grammarians distinguish between clauses containing verbal predicates and clauses containing nonverbal predicates. This results in exhibiting different structures. This classical view of nominal clauses has been adopted by some contemporary linguists (Ingham 1994). Contrary, contemporary linguists argue that both clause types are theoretically verbal/Tensed in their derivational structure. Verbless clauses seem to have undergone some auxiliary verb deleting processes due to the force of some generative syntactic operations, e.g. Topic fronting with the auxiliary being null in present time references (see for example, $\mathrm{Al}$ Zahrani, 2013; 2014a, 2014b). This argument has led to the assumption that all Arabic clauses must have either an overt or covert verbal form. This is on a par with the findings of the growing literature on Arabic dialects; see for example, Aoun et al. (2010), Al Zahrani (2013, 2016), to mention a few. Now, we turn to some examples showing the different subject-verb orders in NA.

The examples in (1) exhibit different word orders. Notice that each example contains a subject, a verb, and a complement with different affixes attached to the verbal root r.s.m

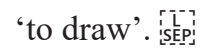

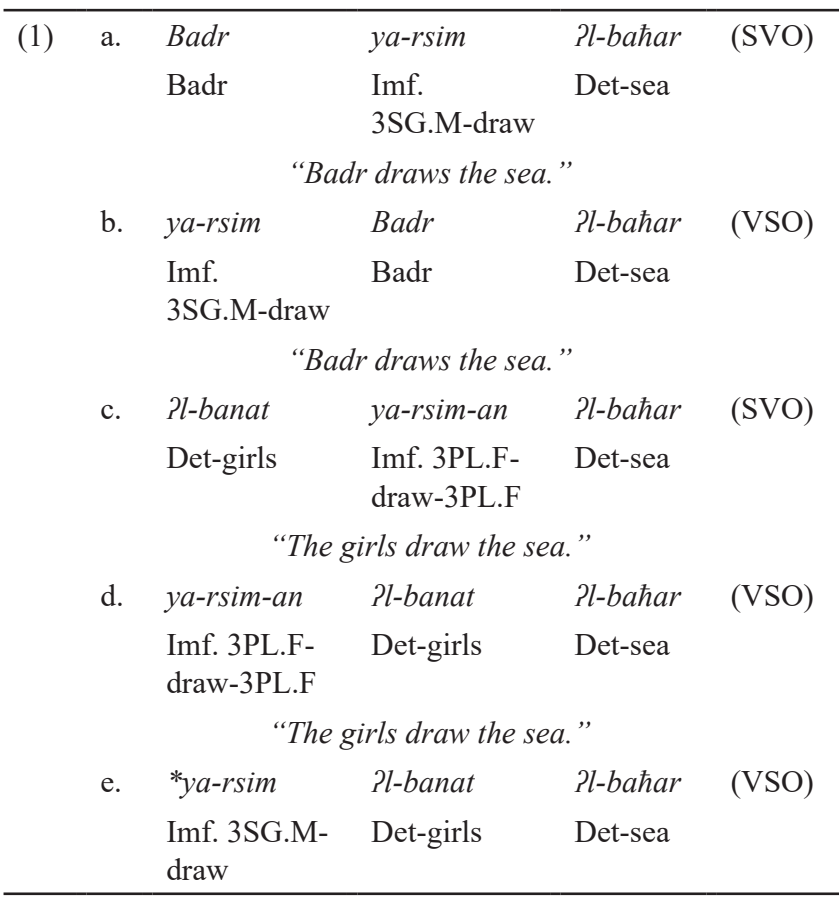

Examples (1a \& 1c) are SVO clauses. They show the topics (mubtada) Badr and Plbanat followed by the verb yarsim 'he draws' and yarsiman 'they draw' respectively. Examples (1b \& 1d) are VSO clauses showing the verb forms followed by their subjects. Each clause in (1) shows full agreement between the verbs and their thematic subjects. The affixes attached to the verb forms show the inflectional markers of person, gender, and number features. The affixes in (1a \& 1b) agree with the third person singular masculine subject Badr; whereas the affixes in (1c \& 1d) mark the third person plural feminine subject ?l-banat 'the girls'. Example (1e) is ungrammatical due to the absence of verb-subject agreement.

What is important to our discussion is that NA clauses show full subject-verb agreement irrespective of the clause word order, be it SVO or VSO. This suggests a difference between Classical/Standard Arabic (C/SA) and NA. The agreement between the verb and its thematic subject in $\mathrm{C} /$ $\mathrm{SA}$ is either full or partial. This agreement variation in $\mathrm{C} /$ $\mathrm{SA}$ is due to the fact that agreement in these varieties of Arabic is highly affected by the word order (Aoun et al. 2010). Consider the SA examples in (2) where VS clauses exhibit partial agreement where only the person and gender features are marked (2a). Contrary, SV clauses exhibit full agreement through the suffix, which marks the person, gender, and number features $(2 \mathrm{~b})$.

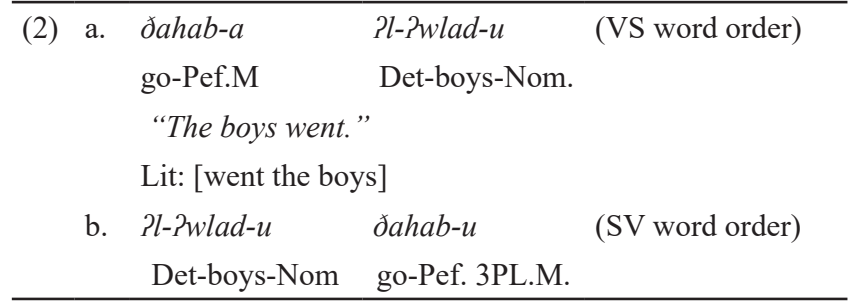

'The boys went.'

In (2a), the suffix $-a$ is attached to the verb ðahab 'go' to express the past tense interpretation and to agree partially with the third-person masculine subject Pl?wladu 'the boys'. There is no indication for the plural number. On the other hand, the suffix $-u$ in (2b) is attached to the verb to mark the full agreement of the third-person plural masculine subject Pl?wladu 'the boys'. The examples in (2) show that SA shows full and partial agreement according to the subject-verb word order. Unlike SA, the examples from NA in (1) show that there is always full subject-verb agreement in both orders (AlQahtani, 2016).

We have, so far, noticed how the affixes exhibit subject-verb agreement features in NA; however, they can also mark some aspectual properties as shown in (3) and (4).

\begin{tabular}{llll}
\hline (3) & Ali & kitab & Pl-wadzib \\
& Ali & write.Pef.3SG.M & Det-homework \\
\hline "Ali wrote the homework." & \\
\hline (4) & Ali & ya-ktib & ?l-wadzib \\
& Ali & Imf.3SG.M-write & Det-homework \\
\hline
\end{tabular}

"Ali writes the homework."

In (3), the verb kitab 'he wrote' expresses that the action is completed (perfective); whereas in (4), the verb 
yaktib 'he writes' expresses that the action is uncompleted (imperfective). The perfective and imperfective verb forms in (3) ad (4) have inflected for person, number, gender, and aspect, and they are associated with past and present time references. Having said this, we follow Al Zahrani (2013) in his assumptions that that there are two main kinds of verb forms: perfective verb forms, which express completed actions and are associated with past-time reference, and imperfective verb forms which express uncompleted actions and are almost always associated with present-time reference. These two verb forms, as shown below, are created by the obligatory movement of verbal roots to merge with aspectual and agreement prefixes and suffixes, which may also create a vocalic change in the syllabic structure of the root.

To apply this, we assume that NA perfective forms are derived by adding personal suffixes to a verbal root, e.g. $k t i b$ - $a w$ 'they.M wrote'. Notice that the third person singular masculine features are morphologically unmarked. The most used pattern for the perfective form is $\left[\mathrm{C}_{1}\right.$ i. $\mathrm{C}_{2}$ a. $\left.\mathrm{C}_{3}\right]$ as kitab (he wrote) or sometimes $\left[\mathrm{C}_{1}\right.$ a. $\mathrm{C}_{2}$ a. $\left.\mathrm{C}_{3}\right]$ ragad (he slept). Imperfective verb forms are derived by adding a prefix to the unmarked perfective masculine form ktib (he wrote); the resulting forms are $y a-k t i b$ 'he writes', ?-ktib 'I write' and ta-ktib 'she writes'. A prefix, on the one hand, and a personal suffix, on the other hand, are both needed to form the second and third person plural masculine/feminine forms, e.ge, $y a-k t i b-u n$ 'they write'. Now the paper moves to discuss the movement operations.

\section{MOVEMENT WITHIN THE MINIMALIST PROGRAM}

In the minimalist program (MP), Agree and Merge are the two basic motivating operations of movement. The first basic operation is Agree, which forms a relation between two constituents. Merge, the second operation, is responsible for forming structures by taking two elements $\mathrm{X}$ and $\mathrm{Y}$ and putting them together to form a new structure $\mathrm{Z}$ (X Y). According to Chomsky (2000, 2001), the two syntactic items are 'Probe' and 'Goal'. The probe triggers the goal it c-commands, hence agreement occurs. Noam Chomsky (2000, 2001) summarises Agree using the following conditions:

$\alpha$ can agree with $\beta$ if and only if:

a. $\quad \alpha$ and $\beta$ carry matching features;

b. $\beta$ is the closest goal to $\alpha$;

c. $\alpha$ c-commands $\beta$ (meaning that $\alpha$ is higher than $\beta$ in the tree structure or at the same height).

Head movement in syntax has been the subject of strong debate in literature for years. Travis (1984), Chomsky (1986) and Pollock (1989) argue that head movement can be briefly explained as raising the head Y of YP to the head X of XP, when XP is dominating YP. A brief illustration is presented in Tree 1.

In Tree 1, the head Y can move higher to the head $\mathrm{X}$ as XP is dominating the projection YP. Recent developments within the MP, particularly by Chomsky (1995), provide a possible solution that does not depend on phonological deficiency. According to Chomsky (1995), tense is specified for the categorical features. This accounts for the dependency

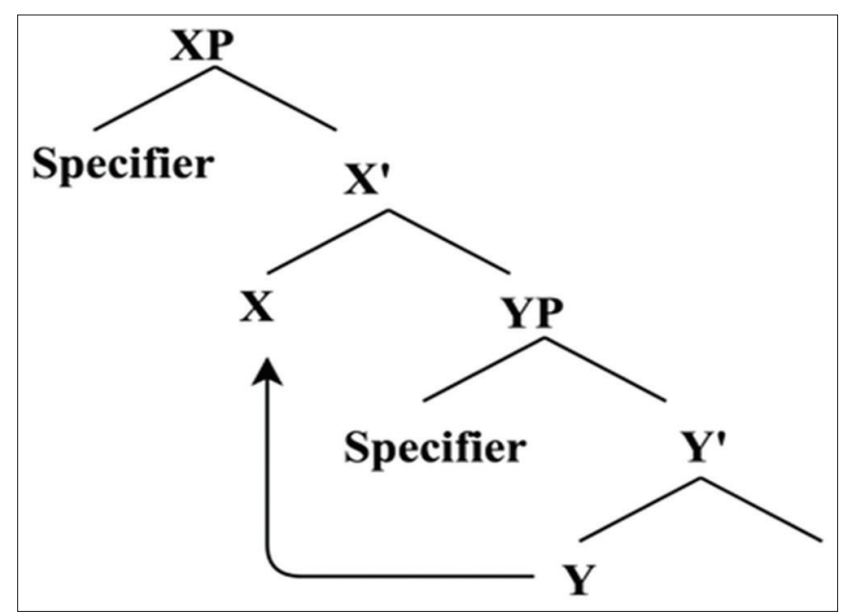

Tree 1. Head Movement

between tense and the subject (EPP) on the one hand, and tense and the verb on the other. The dependency between tense and the subject explains why subject moves to Spec,TP and the dependency between tense and the verb explains $\mathrm{V}$ movement to $\mathrm{T}$ (Aoun et al 2010 P:33).

Turning to NA, a dialect showing VSO and SVO word orders as shown in Section 2, this paper examines the syntactic behaviour of the two types of NA verb forms where verb movement operation is required by projections higher than the VP shell in which verbal roots are base generated. For such an examination, the remaining part of this section summarizes the assumptions and arguments that this paper considers.

Arabic is a verb-raising language, in which the verb movement operation applies (Benmamoun, 2000; Fassi Fehri, 1993; Rahhali \& Souali, 1997). The view that Arabic varieties apply Verb-to-Tense movement is attributed to the assumption that Arabic has rich morphology (Bobaljik, 2000; Ryding, 2005). To explain these fundamental aspects of syntax in this framework, agreement takes place for features that an item needs to be checked and then moved. The literature shows that the verb in Arabic originates as a root in the VP and there is an abstract tense morpheme base-generated in the head of TP. The affixes observed on the verbs are reflexes of agreement features. Thus, as shown in Section 2, agreement features are marked by suffixes on perfective verb forms, and by a prefix indicating person properties and a suffix indicating number properties in imperfective forms (see also, Aoun et al. 2010 and Al Zahrani, 2013). Agreement as a property of language is the focus of many current and recent studies in linguistics, and it (agreement) has been considered a fundamental feature of the syntactic derivation of a clause by many linguists Koopman and Sportiche (1991), McCloskey (1996) Chomsky (2000, 2001). Noam Chomsky (2000, 2001) holds that there is a correlation between rich agreement and the position of the finite verb. The illustration of this view was first advanced in the Rich Agreement Hypothesis (RAH) (Palmer, 1974) which states that a language with a high degree of agreement involves verb movement from its canonical position to T. NA is an example of a dialect with a such rich agreement as shown below.

The paper assumes the set of principles, conditions and constraints that are set in the theory, including the c-com- 
mand relationship and the HMCs, suggested by Travis (1984), which must be very precise with respect to verb movement. Aoun et al (2010), Benmamoun (2002) and Al Zahrani (2013) argue that that the imperfective form is the unmarked form and it appears in different contexts. The imperfective form does not particularly display the present tense. The present tense reference is just one of the imperfective interpretations that can occur, as investigated by some linguists (including Al Zahrani, 2013; Bahloul, 1994; Ouhalla, 1993). Arabic has a TP projection in all main tenses, i.e. past, present, and future. Dominating the TP is the CP layer for which Radford (2009) holds that each complete clause has a null or overt CP layer. Benmamoun (1992) holds that Tense Projection (TP), which is located between $\mathrm{CP}$ and VP, is projected separately from the verb and heading its own projection. Al Zahrani (2013) claims that Arabic functional categories include Tense, Aspect, and Taxis. The latter category has been suggested by Bahloul $(1994,2008)$ for Classical/Modern Standard Arabic structures, and then adopted in more recent work such as Al Zahrani's (2013, 2014a, 2014b, 2016, 2018) for Hijazi Arabic verbal structures. Bahloul combines the Taxis and Aspect projections into one: Tax-AspP where verbs move to check their taxis-aspect features. While Aspect refers to the progression or completeness of the action, Taxis refers to the action time with respect to utterance time. Bahloul (2008) and Al Zahrani (2013) hold that the Arabic Taxis-aspect features are represented through the different (vocalic) affixes attached to the different forms of the verbs. For example, the vocalic affix (a.a.) appears on the unmarked form of the perfective to express the completion of the action, which, in turn, is associated with past time reference. In like fashion, the vocalic affix (ya.i.) appears on the unmarked form of the imperfective to express the incompletion of the action, which may suggest a non-past time reference.

Following the assumptions outlined by Speas (1986), Mohammad (1989), and Koopman and Sportiche (1991) in regard to the Internal Subject Hypothesis, and by Al Zahrani (2013) in regard to Arabic verbs, the paper assumes that the structure of the clause begins in the VP shell where a verbal root originates in the head of VP and its subject originates in Spec, VP. The verb form, be it perfective or imperfective, does not carry tense features. Arabic past and present tenses are not expressed solely by the verb, but by abstract morphemes located in $\mathrm{T}$ and the verbs forms are associated with different tense interpretations (Al Zahrani, 2013). This claim is evidenced by the fact that an imperfective form can occur in many aspectual and temporal contexts where the form does not encode the present tense (Bahloul, 1994) and (Ouhalla, 1993).

Furthermore, the practice of the MP syntactic theory proposed by Chomsky $(1995,2000,2001)$ and its further advancements depends mainly on that the grammar of a language consists basically of lexicon. Forming a clause requires selecting its suitable words from the lexicon. Then, the selected words undergo a number of syntactic operations including the Merge and Move operations. The Merge operation forms larger constituents while the Move operation requires those constituents to move to other positions in the hierarchy according to some specific syntactic purposes. The resulting constituents are then spelled out into PF (phonetic form) and LF (logical form).

In light of this overview of the literature and on what we have adopted for the study of this paper, the structure of NA clauses consists of the following elements. CP dominates TP that dominates AspP that dominates Tax-AspP that dominates VP. The CP layer indicates the force of the clause, i.e. declarative, interrogative, etc.; it is occupied by a null or overt complementizer. However, as this paper does not include any elements occupying $\mathrm{CP}$, we will not include it in the discussion. TP is the locus of the abstract tense features. Tax-AspP containing Taxis, which indicates the time of action, and Aspect, which indicates the completeness of the event indicated by the verb form. Tax-AspP c-commands VP and is the projection responsible for checking phi features through the affixes attached to the verbal roots. This explains why the full agreement is realized between the verb and its thematic subject. The VP shell contains the verbal roots in $\mathrm{V}$, and its arguments: the thematic subject, which is base-generated in the specifier position of VP, and the complement of the head of VP. These projections appear in the hierarchy in Tree 2.

Tree 2 presents the main hierarchy of NA clause structure. The clause starts originally in the VP shell. The verb is in a trilateral form root in V. The subject is in Spec, VP and the DP object is the complement of the verb. Tax-AspP carries the vocalic affixes and $p h i$ features which trigger the verb (in $\mathrm{V}$ ) to undergo some movement operation to TaxAspP and then undergo some merge operation where its root merges with the vocalic affixes. The TP layer includes $\mathrm{T}$ which carries the tense feature. This tense feature can be strong or weak as shown below. Finally, the CP layer marks

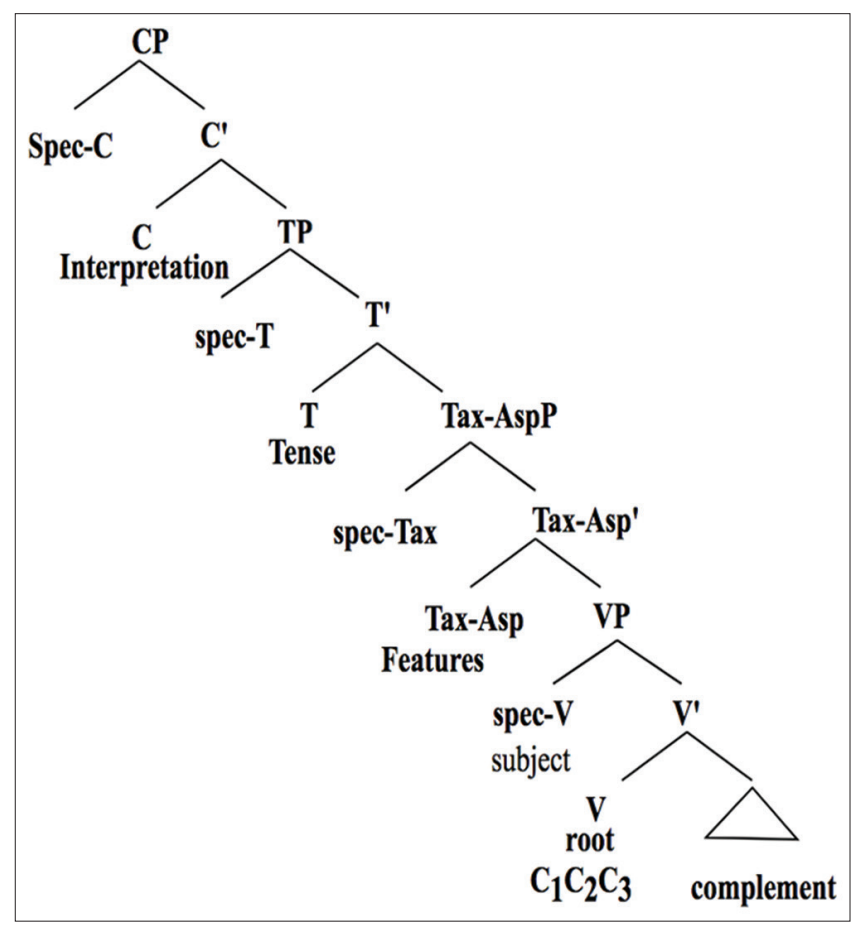

Tree 2. Main hierarchy of NA 
the force of the clause, e.g., declarative/interrogative. The next section examines some data and shows how head movement occurs in NA.

\section{Movement Operation in NA}

Given that Arabic basic word order is VSO, and SVO is an alternative word order (Fassi Fehri, 1993), Ingham (1994) holds that, in NA, the VSO order is used to the same degree as it is in Classical Arabic. It is considered the unmarked word order and it is used in daily spoken language among Najdi people. As explained in Section 3 above, the verb originates as a root in the VP shell. The need for expressing tense-related $p h i$ features requires the verbal root to undergo some movement operation to a position higher than $\mathrm{V}$ as shown in the next sub-section.

\section{Movement Operation Deriving VSO Structures}

Consider the verb forms in (5) and (6).

\begin{tabular}{llll}
\hline (5) & $\begin{array}{l}\text { sakkar-at } \\
\text { close-Pef. 3SG.F }\end{array}$ & $\begin{array}{l}\text { Reema } \\
\text { Reema }\end{array}$ & $\begin{array}{l}\text { addreefah } \\
\text { Det.window }\end{array}$ \\
"Reema closed the window." & & \\
\hline (6) & t-sakkir & Reema & addreefah \\
& Imf.3SG.F-close & Reema & Det.window \\
\hline
\end{tabular}

"Reema closes the window."

In (5), the verb sakkar-at is the perfective form of the root s.k.r. The suffix $-a t$ is added to the verb to fulfil the agreement features between the subject Reema and the verb. The perfective form expresses the completion of the notion of (closing the window), so it is associated with the time reference of the action, which is past. Reema is the subject and addreefah 'the window' is the complement of the verb.

In (6), t-sakkir is the imperfective form of the root s.k.r. The prefix $t$ - marks the third person singular feminine features of the subject Reema. The verb in this clause shows that the action is not completed and the reference time is present. Examples (5) and (6) are represented in Tree (3) and Tree (4) respectively.

Tree 3 and Tree 4 show that the clause structures start from the VP shell, i.e., the verb and its arguments are in the VP layer. The verbal root s.k.r is base-generated in V. The subject Reema is the argument of the verb. According to the Internal Subject Hypothesis (ISH) suggested by Koopman and Sportiche (1991) and its advancement by McCloskey (1996, 1997), the subject occupies Spec,VP, which is preceding the verb position. The object addreefah 'the window' is the complement of the verb. As stated earlier in Section 3, agree is one of the most important motivating operation of verb movement, so the verbal root is obligatory required to move to Tax-Asp where it can infect for agreement with its subject: Reema - third person singular feminine. The TaxAspP projection is the position where verbal roots inflect for aspect and agreement. Tax-AspP in Tree 3 shows that the action of closing the window is completed, and it also indicates the time reference: past. Tax-AspP in Tree 4 shows that the action of closing the window is not completed, which,

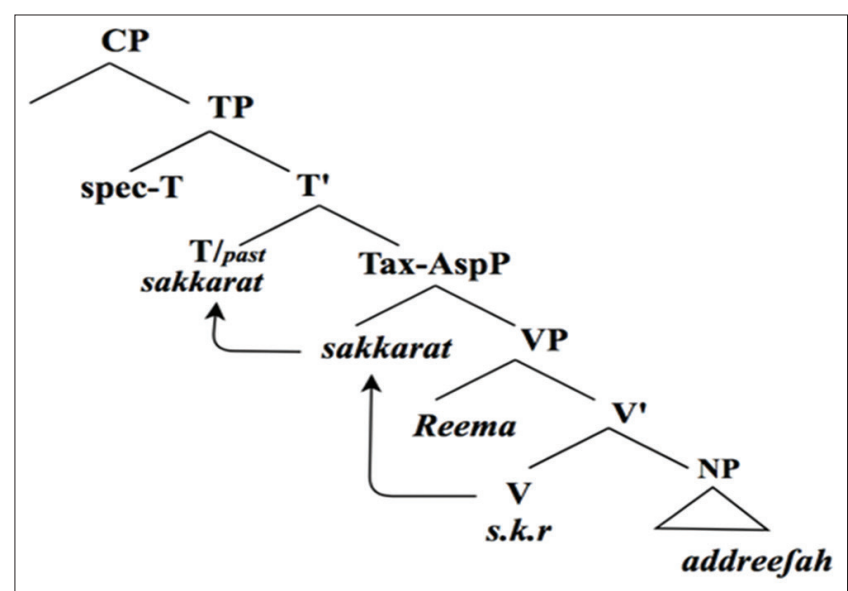

Tree 3. Perfective Verb Movement

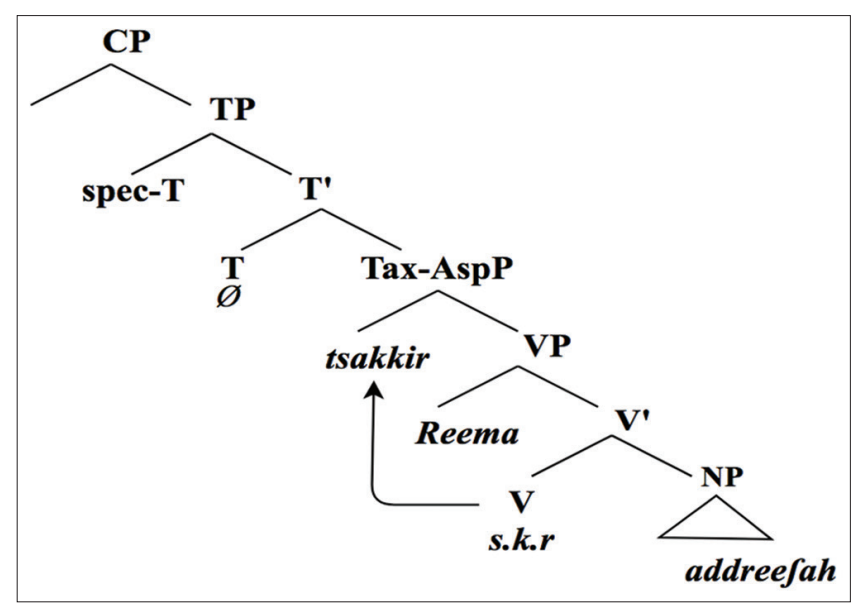

Tree 4. Imperfective Verb Movement

in turn, suggests that the time reference is present. The taxis-aspectual features, time reference properties and agreement features are indicated through the suffix -at in Tree 3, and the prefix $t$ - in Tree 4. This explains why the verbal root is required to move to Tax-AspP and merge with the vocalic melodies [a.a.at] to form a larger constituent - namely, the verb sakkar-at 'she closed' and [t.a.i] t-sakkir 'she closes' in Tress 3 and Tree 4 respectively. Without these two obligatory operations: movement of the verbal root and agreement with the subject, the interpretation of the clause will be merely limited. This explains why Miyagawa (2009) claims that without movement and agreement human language would be no more than a shadow of itself with serious and extreme limitations on expressing human thought.

After the taxis-aspectual features and subject-verb agreement have taken place in Tax-AspP, the past tense feature needs to be hosted by an appropriate perfective form occupying T: the locus of tense. Hence, the past tense features trigger the perfective verb form to move from Tax-Asp to T. This suggests that the past tense feature is strong.

It is important to recall that the verb forms have avoided violating the HMC principle. Thus, the perfective verb has undergone a successive-cyclic movement from $\mathrm{V}$ to $\mathrm{T}$ via Tax-Asp. As for the imperfective form, it is also important to notice that the Arabic present tense feature (in T) is weak so 
it does not trigger an imperfective verb form to move higher. Consequently, non-past verb forms (i.e. imperfective forms) represent the unmarked forms of the verbs as they do not need to move to T (see Al Zahrani (2013) for more details). The $[+\mathrm{V}]$ feature, which is only in the past tense, triggers the verb to move to T (Aoun, Choueiri, \& Benmamoun, 2010) to compose the VS word order, as the subject does not need to move. Rather, the subject stays in-situ within the thematic shell (Spec,VP) since the verb fulfils the agreement (Aoun et al., 2010). If this is the case, following Aoun et al (2010: 50 ), we assume that Spec, TP is empty or occupied by a null expletive ( pro $\left._{\text {exp }}\right)$. The complement addreefah 'the window' stays in situ: as the complement of the head V; hence the derivation of the VSO clause. The point to be made here is that the VSO order is the unmarked word order in NA in that it is derived through an obligatory movement of the verbal root from $\mathrm{V}$ to Tax-Asp (and then to $\mathrm{T}$ if perfective) whereas the verb arguments stay in situ. Now, we move on to show the derivation of the SVO order.

\section{Movement Operations Deriving SVO Structures}

We have stated above that NA clauses exhibit two main word orders: VSO and SVO. We have also concluded in Section 4.1 that the VSO order is the unmarked word order. This section argues that the SVO order is an alternative word order. Consider the examples in (7a-b). They exhibit the SVO word order, which is an alternative version of the VSO represented in (5) \& (6) above.

\begin{tabular}{ccll}
\hline (7) a. $\quad \begin{array}{c}\text { Reema } \\
\text { Reema }\end{array}$ & $\begin{array}{l}\text { sakkar-at } \\
\text { close-Pef. 3SG.F }\end{array}$ & $\begin{array}{l}\text { addreefah } \\
\text { Det.window }\end{array}$ \\
\hline "Reema closed the window." & \\
\hline b. & Reema & t-sakkir & addreefah \\
& Reema & Imf.3SG.F-close & Det.window \\
\hline
\end{tabular}

Forming the SVO word order at this point means that the subject needs to move past the verb in the hierarchy. In other words, there should be some further movement operations in addition to the basic ones discussed in the previous section. There are different approaches to the investigation of the subject placement and its movement in the SVO word order. The dispute between the two approaches departs from the subject-generated position as shown in the next sub-heading.

\section{Movement Operations for SVO within the Domain of TP}

Following traditional grammar, Al-Balushi (2010, 2011), Al-Horais (2009), Soltan (2007, 2009) and AlQahtani (2016) argue that post-verbal DPs are the only subjects in Arabic verbal clauses whereas preverbal DPs are not. In other words, they claim that Spec,VP is the only subject position in VSO clauses; the preverbal DP in SVO clauses is a topic (mubtadaa), not a subject. Evidence for their claim springs from the full agreement between the preverbal DP and the verb. The preverbal DP is base generated in Spec,TP, and that the thematic subject position Spec,VP is occupied by null pro that co-indexes with the preverbal topic base-generated in Spec,TP. Hence, the verb shows full agreement through the morphemes (affixes) attached to it. This full agreement is what identifies the null subject (pro) in Spec,VP. Having assumed that the preverbal DP is a topic, the combination structure of the verb and its object is a predicate (xabar).

The other approach has been adopted by Al Zahrani (2013), Benmamoun (2000), Fassi Fehri (1993), \& Koopman and Sportiche (1991) amongst others. They argue that the subject is originated in Spec,VP, and it may move to Spec, TP to form the alternative SVO word order. Once it has moved, it leaves a trace. Accordingly, the subject can have two positions within the hierarchy: Spec, VP or Spec,TP.

Evidence in support of this claim, which we follow in this paper, springs from the Economy Condition of the Minimalist Program that states that "syntactic structures should contain as few words as possible, and syntactic operations should affect as few words as possible" (Radford, 2009: 56). Therefore, movement should be as economic as possible and there should be no movement if it is not triggered by some syntactic operations and/or requirements. While the movement of the subject to Spec,TP is obligatory in some languages, like French and English, to fulfil the EPP features and absorb the nominative case, it is optional in NA, as is the case in HA and some Arabic varieties where the subject absorbs the default nominative case in its thematic position: Spec,VP. The obligatory movement of the subject to satisfy the EPP features and assign the nominative case in Spect,TP in some languages does not clash with the Economy Condition. Otherwise, if the subject stays in its thematic position (Spec,VP) and the verb moves to $\mathrm{T}$ in English, for instance, the resulting structure is $\mathrm{VSO}$, which is an ungrammatical structure in English (Cf. *go I to school). However, if NA clauses can present the VSO word order and the subject can be assigned nominative case in its thematic position, there is no trigger for the subject to move to Spec,TP. Hence, it stays in-situ in Arabic.

To conclude this view, the subject in NA absorbs its default nominative case in Spec,VP and the movement from Spec,VP to Spec, TP is optional, and once achieved, it forms an alternative word order, i.e., SVO, as the following linear representations in (8) show for the examples in (7a-b) respectively.

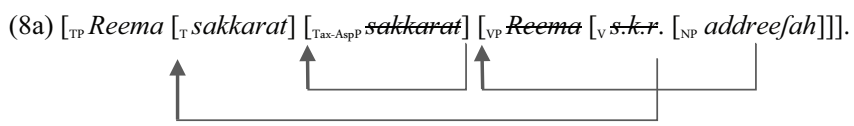

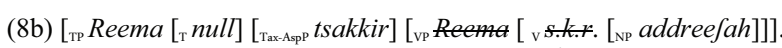

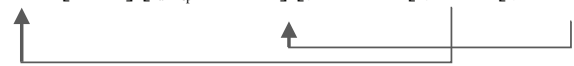

The linear representations in (8) show the following movement operations: (i) the successivecyclic movement of the perfective verb form from its base generated position in the head of VP to T via Tax-Asp (8a), (ii) the movement of the imperfective form from its base generated position in the head of VP to Tax-Asp; T is null (8b); (iii) the movement operation of the subject Reema from its original position in Spec,VP to Spec TP (8a-b) to derive the alternative SVO word order. These operations are represented in Tree (5) \& Tree (6) below. 


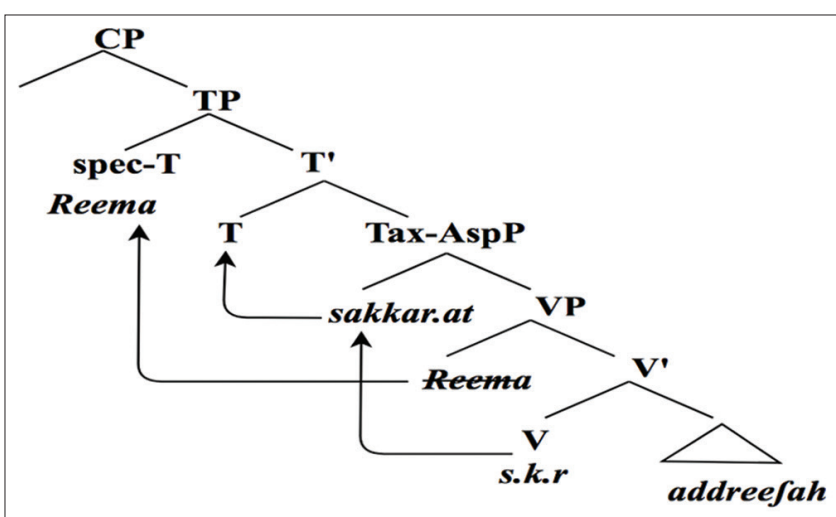

Tree 5. Subject movement with a perfective form

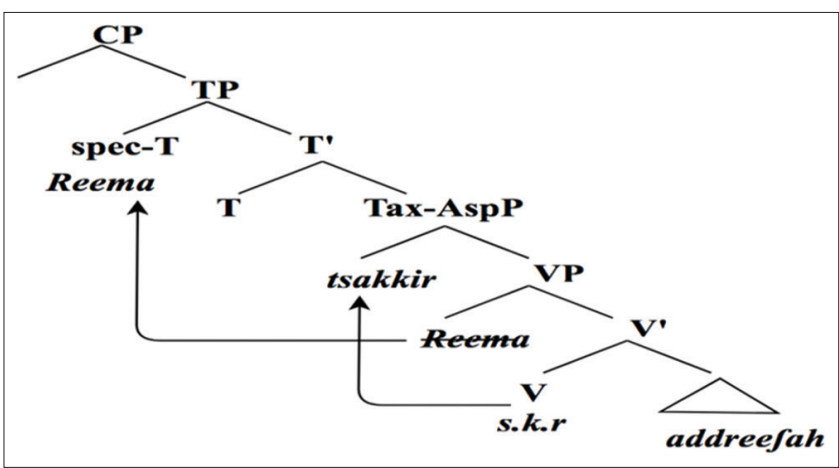

Tree 6. Subject movement with an imperfective form

Trees $5 \& 6$ show the movement operations in the clauses containing a perfective and an imperfective verb form respectively. After the verb movement has taken place, the subject moves to Spec,TP. In Tree 5, the perfective form moves to T via Tax-AspP. In Tree 6, the imperfective verb form moves only to Tax-AspP but not to $\mathrm{T}$ as the present tense feature does not require a morphological form in $\mathrm{T}$.

\section{CONCLUSION}

This current study has analysed some NA data to explore the obligatory verb movement operation that in turn derives the basic word structure: VSO. This exploration has resulted in proposing the derivation of the alternative SVO order. The analysis has shown that the derivation of clauses in NA starts out from the head of the VP shell, which is the basegenerated position of verbal roots. The thematic subject, which is the argument of the verb, is base-generated in Spec,VP. When the subject moves higher in the hierarchy, it ccommands the verb and it establishes an agreement relation with the verb. When the verb moves from its position in $\mathrm{V}$ to Tax-AspP it merges with the affixes located in Tax-AspP to inflect for aspectual and agreement features. If perfective, the strong past-tense feature located in $\mathrm{T}$ triggers the perfective verb form to move higher to T. It should be noted that the perfective verb obeys the HMC in that it moves in a successive-cyclic fashion to $\mathrm{T}$ via TaxAspP. The imperfective forms do not need to move to $\mathrm{T}$ because the latter does not require a morphological form if the tense is present. This, in turn, proposes that imperfective forms constitute the unmarked form of the verbs. The alternative SVO word order is achieved by a further movement operation in which the subject moves higher than the verb. The resulting structure is the one where the subject moves from its position in Spec,VP to Spec,TP.

\section{REFERENCES}

Al-Balushi, R. (2010). The licensing of structural case in Standard Arabic. Canadian Linguistic Association.

Al-Balushi, R. (2011). Case in standard Arabic: The untraveled paths. (PhD), University of Toronto.

Al-Horais, N. (2009). A minimalist approach to agreement in Arabic. Newcastle Working Papers in Linguistics, 15, $1-21$.

Al Zahrani, M. (2013). Morphosyntactic and Semantic Properties of Hijazi Arabic Modals. (PhD Theoretical Linguistics: Morpho-Syntax and Semantics Interface), University of Queensland, Brisbane, Queensland.

Al Zahrani, M. (2014a). Negation in Non-Verbal ClausesModern Standard Arabic (MSA) and Spoken Hijazi Arabic (SHA). Pakistan Journal of Languages and Translation Studies, 2, 31- 49.

Al Zahrani, M. (2014b). The syntactic Properties of Negatives. US-China Foreign Language(1), 1-17.

Al Zahrani, M. (2016). Aktionsarten Projection and Subcategorization. The Internaional Journal of Arabic Linguistics (IJAL), 2(1), 46 - 69.

Al Zahrani, M. (2018). Morphosyntactic and Semantic Properties of Epistemic Modals modifying Verbal Clauses. In P. G. Medina, R. T. Alonso \& R. V. Escarza (Eds.), Verbs, Clauses and Constructions: Functional and Typological Approaches (pp. 149 - 166). Newcastle: United Kingdom: Cambridge Scholars Publishing.

AlQahtani, S. J. (2016). The Structure and Distribution of Determiner Phrases in Arabic: Standard Arabic and Saudi Dialects. (PhD), University of Ottawa.

Aoun, J., Choueiri, L., \& Benmamoun, E. (2010). The syntax of Arabic. New York: Cambridge University Press.

Bahloul, M. (1994). The Syntax and Semantics of Taxis, Aspect, Tense and Modality in Standard Arabic. (PhD $\mathrm{PhD})$, Cornell University.

Bahloul, M. (2008). Structure and Function of the Arabic Verb. London: Routledge.

Benmamoun, E. (1992). Functional and Inflectional Morphology: Problems of Projection, Representation and Derivation. (Ph.D), USC, Los Angeles.

Benmamoun, E. (2000). The feature structure of functional categories : a comparative study of Arabic dialects. New York: Oxford University Press.

Bobaljik, J. D. (2000). The rich agreement hypothesis in review. Ms., McGill University.

Chomsky, N. (1986). Barriers. Cambridge, Massachusetts: M.I.T. Press.

Chomsky, N. (1995). The minimalist program. Cambridge, Mass.: The MIT Press.

Chomsky, N. (2000). Minimalist Inquiries. In R. M. e. al (Ed.), Step by Step: Essays on Minimalist Syntax in Honor of Howard Lasnik (pp. 53-87). Cambridge, Massachusetts: M.I.T. Press. 
Chomsky, N. (2001). Derivation by Phase. In M. Kenstowicz (Ed.), Ken Hale: A Life in Language (pp. 13-127 ). Cambridge, Massachusetts: M.I.T. Press.

Fassi Fehri, A. (1993). Issues in the Structure of Arabic Clauses and Words. Dordrecht: Kluwer Academic Publishers.

Hassan, A. (1987). Al Nahw Al-Wafi. Cairo: Daar Al-Ma'aarif.

Kayne, R. S. (1994). The antisymmetry of syntax. Cambridge, Mass.: MIT Press.

Koopman, H., \& Sportiche, D. (1991). The positions of subjects. Lingua(85), 211-258.

McCloskey, J. (1996). Subjects and subject positions. In R. B. a. I. Roberts (Ed.), The Syntax of the Celtic Languages (pp. 241-243): Cambridge University Press.

McCloskey, J. (1997). Subjecthood and subject positions. In L. Haegeman (Ed.), Elements of grammar: a handbook of generative syntax (pp. 197-235): Dordrecht: Kluwer.

Miyagawa, S. (2009). Why Agree? Why Move?: Unifying Agreement-Based and Discourse-Configurational Languages: MIT Press.

Mohammad, M. A. (1989). The sentential structure of Arabic. (Thesis ( $\mathrm{Ph} \mathrm{D} \mathrm{)),} \mathrm{University} \mathrm{of} \mathrm{Southern} \mathrm{California}$ Library, Los Angeles, Calif.

Ouhalla, J. (1993). Negation, Focus and Tense: The arabic laa and maa. Rivisita di Linguistica, 5.
Palmer, F. R. (1974). The English verb (2d ed.). London: Longman.

Pollock, J.-Y. (1989). Verb Movement, Universal Grammar, and the Structure of IP. Linguistic Inquiry (20), 365-424.

Radford, A. (2009). An introduction to English sentence structure. Cambridge, UK ; New York: Cambridge University Press.

Rahhali, M., \& Souali, E. H. (1997). A Minimalist approach to verb Movement in Standard Arabic. Studia Linguistica, 51(3), 317-338.

Ryding, K. C. (2005). A Reference Grammar of Modern Standard Arabic. Cambridge Cambridge University Press.

Soltan, O. (2007). On formal feature licensing in minimalism: aspects of Standard Arabic morphosyntax. (PhD), University of Maryland, College Park.

Soltan, O. (2009). Agree in the Functional Domain: Evidence from the Morphosyntax of Positive and Negative Imperatives in Standard Arabic. Afrrican Linguistics.

Speas, M. J. (1986). Adjuncts and projections in syntax. (PhD), Unpublished $\mathrm{PhD}$ thesis, Massachusetts Institute of Technology Unpublished $\mathrm{PhD}$ thesis.

Travis, L. (1984). Parameters and Effects of Word Order Variation. (PhD), MIT, Mass. 